\title{
Prognostic role of microRNAs in human gastrointestinal cancer: A systematic review and meta-analysis
}

\author{
Qiang Zheng ${ }^{1, *}$, Changyu Chen ${ }^{2, *}$, Haiyang Guan ${ }^{3}$, Weibiao Kang ${ }^{1}$ and Changjun $\mathbf{Y u}^{1}$ \\ ${ }^{1}$ Department of Gastrointestinal Surgery, First Affiliated Hospital of Anhui Medical University, Hefei, China \\ 2 Department of General Surgery, First Affiliated Hospital of Anhui Traditional Medical University, Hefei, China \\ ${ }^{3}$ Hefei National Laboratory for Physical Sciences at Microscale and School of Life Sciences, University of Science and \\ Technology of China, Hefei, China \\ * These authors have contributed equally to this work \\ Correspondence to: Changjun Yu, email: changjuyu212@163.com \\ Keywords: microRNAs, prognosis, gastrointestinal cancer, target, meta-analysis \\ Received: October 31, $2016 \quad$ Accepted: March 09, $2017 \quad$ Published: March 29, 2017
}

Copyright: Zheng et al. This is an open-access article distributed under the terms of the Creative Commons Attribution License 3.0 (CC BY 3.0), which permits unrestricted use, distribution, and reproduction in any medium, provided the original author and source are credited.

\section{ABSTRACT}

Background: Gastrointestinal cancers (GICs) mainly including esophageal, gastric and colorectal cancer, are the most common cause of cancer-related death and lead into high mortality worldwide. We performed this systematic review and metaanalysis to elucidate relationship between multiple microRNAs (miRs) expression and survival of GIC patients.

Methods: We searched a wide range of database. Fixed-effects and randomeffects models were used to calculate the pooled hazard ratio values of overall survival and disease free survival. In addition, funnel plots were used to qualitatively analyze the publication bias and verified by Begg's test while it seems asymmetry.

Results: 60 studies involving a total of 6225 patients (1271 with esophageal cancer, 3467 with gastric cancer and 1517 with colorectal cancer) were included in our meta-analysis. The pooled hazard ratio values of overall survival related to different miRs expression in esophageal, gastric, colorectal and gastrointestinal cancer were 2.10 (1.78-2.49), 2.02 (1.83-2.23), 2.54 (2.14-3.02) and 2.15 (1.992.31), respectively. We have identified a total of 59 miRs including 23 significantly up-regulated expression miRs (miR-214, miR-17, miR-20a, miR-200c, miR-107, miR$27 \mathrm{a}$, etc.) and 36 significantly down-regulated expression miRs (miR-433, let-7g, miR-125a-5p, miR-760, miR-206, miR-26a, miR-200b, miR-185, etc.) correlated with poor prognosis in GIC patients. Moreover, 35 of them revealed mechanisms.

Conclusion: Overall, specific miRs are significantly associated with the prognosis of GIC patients and potentially eligible for the prediction of patients survival. It also provides a potential value for clinical decision-making development and may serve as a promising miR-based target therapy waiting for further elucidation.

\section{INTRODUCTION}

Gastrointestinal cancers (GICs) mainly including esophageal cancer (EC), gastric cancer (GC) and colorectal cancer (CRC), are the most common cause of cancerrelated death leading into high mortality worldwide, and it is still among the highest threatening risk of public health for past decades [1]. Actually, GIC patients at early stage could be cured successfully by receiving proper treatment (adjuvant chemotherapy or radiotherapy after radical resection) following approximately $90 \%$ fiveyear overall survival rate. However, five-year overall survival rate will decline to merely $15 \%$ when develop into advanced stage $[2,3]$. Therefore, early diagnosis and prediction of individual prognosis play pivotal roles in the treatment and recovery of patients. However, there still lack of effective methods to evaluate the prognosis of GIC patients based on clinicopathology. Currently, increasing 
studies have reported that aberrant expression of specific microRNAs (miRs) as stable molecular biomarkers was associated with the prognosis of GIC patients and related to the targeted therapy, which provides potentially novel prevention strategies and advanced therapies [4-6].

Recently, near 8000 human miRs are registered in miRBase (http://www.mirbase.org/), and they regulate approximately $30 \%$ of all gene expression [7]. MiR is a short (20-24 nucleotides) class of non-coding RNA that can target 3'-untranslated regions (3'-UTRs) of mRNA and regulate its expression by degrading a mRNA or suppressing its translation [8,9]. Additionally, one kind of miR can target several kinds of mRNAs at posttranscriptional level. For example, upregulated miR-377 expression promotes tumor proliferation by targeting P53, PTEN and TIMP1 [10]. Meanwhile, various miRs could target identical gene. Furthermore, miR plays a key role in the proliferation and progression of tumor cells, which not only mediates the cells growth, invision, migration and apoptosis but also induces resistance of anticancer drug [11]. For example, down-regulated miR-23b-3p induces chemo-resistence of gastric cancer cells [12]. In addition, many studies have reported that different miRs can be prognostic biomarkers in a wide range of human cancers (ovarian cancer, breast cancer, esophageal cancer, etc.) [13-17].
At present, accumulative evidences have demonstrated that abnormal expression of miRs as stable molecular biomarkers presented potential huge prognostic values in GIC patients [18-23]. However, these monocentric, small sample size studies and various experimental protocols from different research departments limited the ability of evaluating relationship between multiple miRs expression and prognosis of GIC patients. The aim of this paper was to elucidate relationship between multiple miRs expression and prognosis of patients and investigate the possible utility of miRs as prognostic biomarkers in GIC patients. Moreover, further understanding of prognostic value of miRs could help for clinical decision-making and develop miR-based target therapeutic treatments.

\section{RESULTS}

\section{Study identification and characteristics}

60 studies (12 EC, 35 GC and 13 CRC) involving a total of 6255 patients (1271 with EC, 3467 with GC and 1517 with $\mathrm{CRC}$ ) were included in our meta-analysis based on selection criteria and specific steps were presented in Figure 1 [1, 2, 10-12, 16, 18-71]. More than

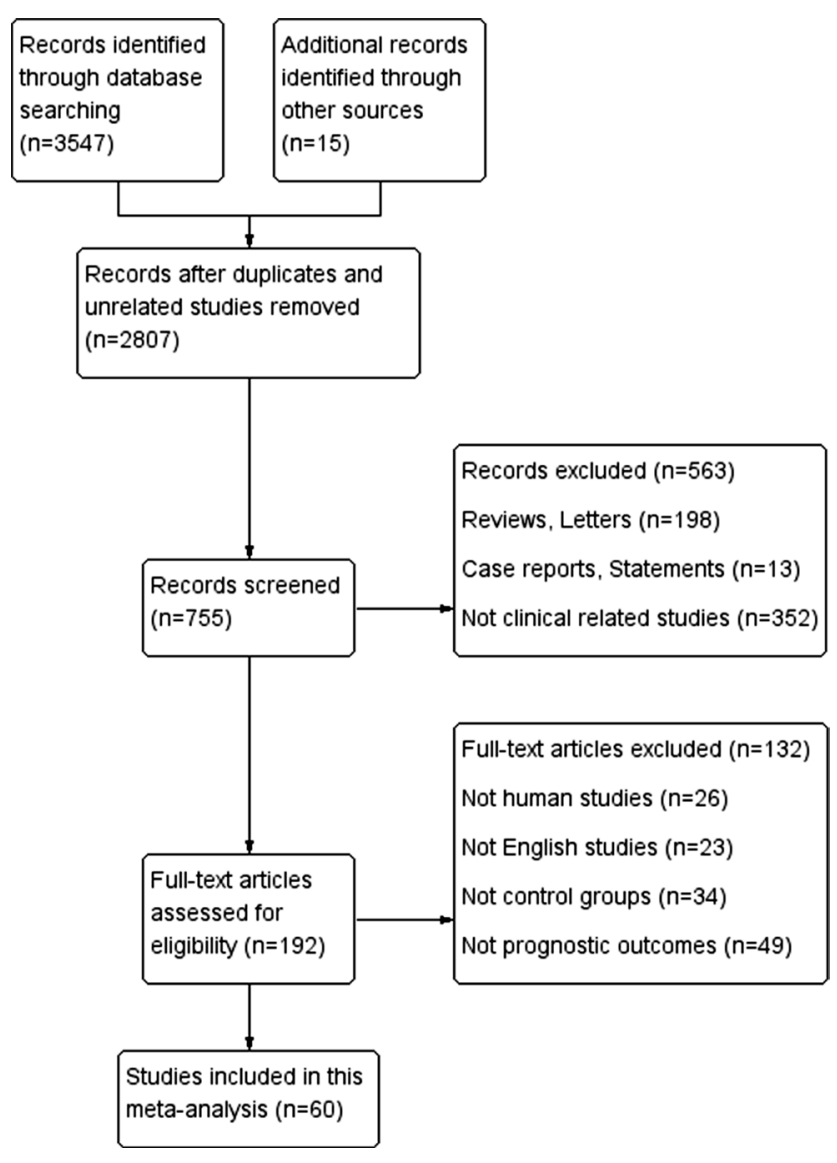

Figure 1: Study flow diagram 
Table 1: Characteristics of studies and different miRs expression related to OS in GIC patients

\begin{tabular}{|c|c|c|c|c|c|c|c|c|c|c|}
\hline \multirow{2}{*}{ References } & \multirow{2}{*}{ Year } & \multirow{2}{*}{$\begin{array}{c}\text { MiRs } \\
(n=54)\end{array}$} & \multirow{2}{*}{ Nations } & \multirow{2}{*}{\begin{tabular}{|c|} 
Number \\
$(n=6125)$ \\
\end{tabular}} & \multicolumn{2}{|r|}{ OS } & \multirow{2}{*}{$\begin{array}{c}\text { Cut-off } \\
\text { value }\end{array}$} & \multirow{2}{*}{$\begin{array}{c}\text { Detection } \\
\text { methods }\end{array}$} & \multirow{2}{*}{\begin{tabular}{|c|} 
Sample \\
types \\
\end{tabular}} & \multirow{2}{*}{$\begin{array}{c}\text { Follow } \\
\text { up }\end{array}$} \\
\hline & & & & & HR* $^{*}$ & $95 \%$ CI & & & & \\
\hline \multirow[t]{2}{*}{ Schetter [24] } & 2008 & $\operatorname{miR}-21 \uparrow$ & USA & CRC 71 & $2.70 *$ & $1.30-5.50$ & Third tertile & RT-PCR & tissue & $<80$ \\
\hline & & $\operatorname{miR}-21 \uparrow$ & China & CRC 103 & $2.40 *$ & $1.40-4.10$ & Dichotomize & Microarray & tissue & $<80$ \\
\hline Mathé [25] & 2009 & $\operatorname{miR}-21 \uparrow$ & USA & EC 69 & $4.71 *$ & $1.74-12.79$ & Dichotomize & RT-PCR & tissue & $<60$ \\
\hline Toiyama [26] & 2013 & 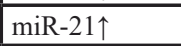 & Japan & CRC 168 & $4.12 *$ & $1.10-15.40$ & YI & RT-PCR & serum & $<60$ \\
\hline Oue [27] & 2014 & $\operatorname{miR}-21 \uparrow$ & \begin{tabular}{|l|} 
Japan \\
\end{tabular} & CRC 156 & $1.80^{*}$ & 0.91-3.58 & Third tertile & RT-PCR & tissue & $<60$ \\
\hline${ }^{\mathrm{a}}$ Wang [16] & 2015 & $\operatorname{miR}-21 \uparrow$ & China & GC 50 & 1.89 & $1.17-3.07$ & mean & RT-PCR & tissue & $<12$ \\
\hline $\mathrm{Hu}[28]$ & 2011 & $\mathrm{miR}-30 \mathrm{e} \uparrow$ & China & EC 158 & 1.80 & $1.26-2.57$ & median & ISH & tissue & $1-256$ \\
\hline Lin [29] & 2012 & miR-142-3p $\uparrow$ & China & EC 91 & $1.90^{*}$ & $1.10-3.31$ & median & RT-PCR & tissue & $<70$ \\
\hline Yokobori [30] & 2012 & 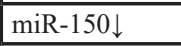 & \begin{tabular}{|l|} 
Japan \\
\end{tabular} & EC 108 & 1.71 & $0.88-3.33$ & median & RT-PCR & tissue & $1-128$ \\
\hline Gong [31] & 2013 & miR-138 $\downarrow$ & China & EC 205 & 1.76 & $1.20-2.59$ & median & RT-PCR & tissue & $<120$ \\
\hline Takeshita [32] & 2013 & miR-1246个 & Japan & EC 101 & 4.03 & $1.28-12.73$ & median & RT-PCR & serum & $<24$ \\
\hline Akanuma [33] & 2014 & miR-134a $\downarrow$ & \begin{tabular}{|l|} 
Japan \\
\end{tabular} & EC 84 & 2.05 & \begin{tabular}{|l|}
$1.02-4.11$ \\
\end{tabular} & median & RT-PCR & tissue & $<120$ \\
\hline Lin [34] & 2014 & miR-508 $\uparrow$ & China & EC 207 & 3.12 & $2.06-4.75$ & median & RT-PCR & tissue & $<60$ \\
\hline Sun [35] & 2014 & 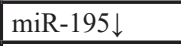 & China & EC 98 & 5.96 & $1.26-11.93$ & median & RT-PCR & tissue & $1-63$ \\
\hline Ide [36] & 2015 & miR-503个 & Japan & EC 61 & $4.13 *$ & $1.47-11.33$ & median & RT-PCR & tissue & $<80$ \\
\hline Ge [37] & 2015 & miR-942 $\uparrow$ & China & EC 158 & 1.88 & $1.19-2.96$ & median & RT-PCR & tissue & $<80$ \\
\hline \multirow[t]{3}{*}{ Ueda [38] } & 2010 & miR-214个 & Japan & GC 184 & 2.40 & $1.20-4.50$ & median & RT-PCR & tissue & 5-102 \\
\hline & & miR-433 $\downarrow$ & & & 2.10 & $1.10-3.90$ & median & RT-PCR & tissue & 5-102 \\
\hline & & let-7g $\downarrow$ & & & 2.60 & $1.30-4.90$ & median & RT-PCR & tissue & $5-102$ \\
\hline Nishida [39] & 2011 & miR-125a-5p $\downarrow$ & \begin{tabular}{|l|} 
Japan \\
\end{tabular} & GC 87 & 1.87 & 0.95-3.66 & mean & RT-PCR & tissue & 1-148 \\
\hline Ayerbes [1] & 2011 & miR-17个 & Spain & GC 38 & 2.62 & 1.55-4.49 & mean & RT-PCR & $\mathrm{BM}$ & $1-97$ \\
\hline \multirow[t]{2}{*}{ Wang [20] } & 2012 & miR-17-5p $\uparrow$ & China & GC 65 & 1.79 & 1.11-2.87 & median & RT-PCR & plasma & $<34$ \\
\hline & & $\mathrm{miR}-20 \mathrm{a} \uparrow$ & & & $1.58^{*}$ & $1.10-2.25$ & median & RT-PCR & plasma & $<36$ \\
\hline Ayerbes [18] & 2012 & $\operatorname{miR}-200 \mathrm{c} \uparrow$ & Spain & GC 52 & $2.24 *$ & $1.09-4.61$ & mean & RT-PCR & blood & $6-53$ \\
\hline Inoue [23] & 2012 & miR-107^ & Japan & GC 161 & $0.45^{*}$ & $0.22-0.85$ & mean & RT-PCR & tissue & 6-72 \\
\hline Iwaya [40] & 2013 & miR-760 $\downarrow$ & Japan & GC 82 & 1.67 & 1.03-3.11 & median & RT-PCR & BM & $<72$ \\
\hline Yang [2] & 2013 & miR-206 $\downarrow$ & China & GC 98 & 2.60 & $1.80-5.80$ & mean & RT-PCR & tissue & 6-139 \\
\hline Deng [41] & 2013 & miR-26a $\downarrow$ & China & GC 126 & 2.55 & $1.57-4.16$ & 2 fold & ISH & tissue & $24-60$ \\
\hline Tang [42] & 2013 & miR-200b $\downarrow$ & China & GC 36 & 2.08 & $1.28-3.37$ & 2 fold & ISH & tissue & 23-59 \\
\hline Tan [43] & 2013 & miR-185 $\downarrow$ & China & GC 36 & 2.33 & $0.99-5.47$ & median & ISH & tissue & $32-58$ \\
\hline Huang [44] & 2013 & miR-27a $\uparrow$ & China & GC 82 & 1.75 & $1.02-3.01$ & NR & RT-PCR & serum & $<20$ \\
\hline Lim [45] & 2013 & miR-196b $\uparrow$ & China & GC 60 & 1.87 & $0.17-20.14$ & median & Microarray & tissue & $35-76$ \\
\hline Wang [46] & 2013 & 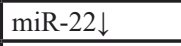 & \begin{tabular}{|l} 
China \\
\end{tabular} & GC 98 & $2.20^{*}$ & \begin{tabular}{|l|}
$0.60-5.20$ \\
\end{tabular} & mean & RT-PCR & tissue & 6-139 \\
\hline $\mathrm{Fu}[21]$ & 2014 & miR-222؟ & China & GC 114 & $3.41 *$ & $1.84-6.16$ & median & RT-PCR & plasma & $18-60$ \\
\hline Yang [47] & 2014 & miR-106b $\uparrow$ & China & GC 120 & 1.64 & $1.02-2.61$ & median & Microarray & tissue & $2-40$ \\
\hline Cheng [48] & 2014 & 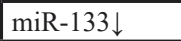 & China & GC 180 & 1.85 & $0.60-5.70$ & mean & RT-PCR & tissue & $38-60$ \\
\hline Xin [49] & 2014 & miR-218 $\downarrow$ & China & GC 68 & $3.16^{*}$ & 1.06-9.40 & mean & RT-PCR & serum & $<36$ \\
\hline Chen [50] & 2015 & 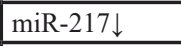 & China & GC 83 & 2.63 & \begin{tabular}{|l|}
$1.18-4.34$ \\
\end{tabular} & median & RT-PCR & tissue & $<90$ \\
\hline Zhang [51] & 2015 & miR-500个 & China & GC 323 & 2.23 & $1.66-3.23$ & median & RT-PCR & tissue & $<60$ \\
\hline Deng [52] & 2015 & miR-506 $\downarrow$ & China & GC 63 & 1.53 & 0.53-4.39 & median & RT-PCR & tissue & $22-77$ \\
\hline $\mathrm{Gu}[22]$ & 2015 & 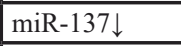 & China & GC 87 & 3.74 & $1.81-7.73$ & median & RT-PCR & tissue & $<96$ \\
\hline Li [53] & 2015 & miR-326 $\downarrow$ & China & GC 136 & $1.51^{*}$ & $1.08-2.76$ & median & RT-PCR & tissue & $8-93$ \\
\hline Chen [54] & 2015 & miR-486-5p $\downarrow$ & China & GC 84 & $3.61 *$ & 1.99-6.54 & median & ISH & tissue & $1-75$ \\
\hline${ }^{a}$ Wang [16] & 2015 & 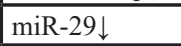 & China & GC 50 & 2.23 & $1.34-3.65$ & mean & RT-PCR & tissue & $<12$ \\
\hline WEN [10] & 2015 & miR-377^ & China & GC 102 & $2.14 *$ & $0.87-4.42$ & mean & RT-PCR & tissue & $<60$ \\
\hline Gong [55] & 2015 & $\operatorname{miR}-25 \uparrow$ & China & GC 40 & 2.04 & $0.80-5.10$ & mean & RT-PCR & tissue & $36-61$ \\
\hline An [12] & 2015 & miR-23b-3p $\downarrow$ & China & GC 140 & 2.07 & 1.14-3.76 & NR & ISH & tissue & $1-56$ \\
\hline Chen [56] & 2015 & 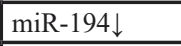 & China & GC 76 & 3.23 & $1.20-8.71$ & mean & RT-PCR & tissue & 26-84 \\
\hline $\mathrm{Su}[57]$ & 2015 & miR-451 $\downarrow$ & China & GC 107 & 1.03 & $0.52-2.02$ & mean & RT-PCR & tissue & 19-74 \\
\hline Shi [58] & 2015 & miR-206 $\downarrow$ & China & GC 220 & $6.82 *$ & $1.51-21.29$ & mean & RT-PCR & tissue & $<60$ \\
\hline Hui [59] & 2015 & miR-34a $\downarrow$ & China & GC 76 & $2.33 *$ & $1.10-4.93$ & median & RT-PCR & tissue & $<60$ \\
\hline Imaoka [19] & 2015 & 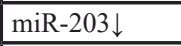 & Japan & GC 130 & $4.51 *$ & $1.23-23.69$ & $\mathrm{YI}$ & RT-PCR & serum & $1-78$ \\
\hline Diaz [60] & 2008 & miR-106a $\downarrow$ & Spain & CRC 110 & $1.90^{*}$ & $0.93-3.80$ & median & RT-PCR & tissue & 68-99 \\
\hline Nishimura [61] & 2012 & miR-181a $\uparrow$ & \begin{tabular}{|l|} 
Japan \\
\end{tabular} & CRC 162 & 2.36 & 0.81-6.85 & median & RT-PCR & tissue & $36-60$ \\
\hline Guo [11] & 2013 & 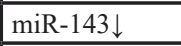 & China & CRC 79 & 2.73 & $0.68-10.96$ & median & RT-PCR & tissue & $41-122$ \\
\hline Zhou [62] & 2013 & miR-183个 & China & CRC 94 & $2.75^{*}$ & $1.12-6.33$ & mean & Microarray & tissue & $<70$ \\
\hline
\end{tabular}




\begin{tabular}{|l|l|l|l|l|l|l|l|l|l|l|}
\hline Qian [63] & 2013 & miR-16 $\downarrow$ & China & CRC 143 & 2.59 & $2.14-3.35$ & mean & RT-PCR & tissue & $<120$ \\
\hline Liu [64] & 2014 & miR-139-3p $\downarrow$ & China & CRC 63 & $2.79^{*}$ & $1.01-7.76$ & mean & RT-PCR & tissue & $<80$ \\
\hline Ma [65] & 2014 & miR-361-5p $\downarrow$ & China & CRC 60 & $\mathbf{2 . 2 4}$ & $0.48-10.50$ & mean & RT-PCR & tissue & $3-60$ \\
\hline Gopalan [66] & 2014 & miR-1288 $\uparrow$ & Australia & CRC 122 & $\mathbf{1 . 6 1}$ & $0.14-19.23$ & 2-fold & RT-PCR & tissue & $10-68$ \\
\hline
\end{tabular}

${ }^{a}$ One study involved both miR-29 and miR-21; * = adjusted HR; $\uparrow$ or $\downarrow$ up-regulated or down-regulated with poor prognosis; GIC gastrointestinal cancer; EC esophageal cancer; GC gastric cancer; CRC colorectal cancer; OS overall survival; HR hazard ratio; NR not report; YI Youden index; RT-PCR reverse transcription PCR; ISH in sit hybridization; BM bone marrow; Calculated HR of OS was in bold.

half of included studies were from East Asian countries. Detection methods of miRs expression were mostly reverse transcription PCR (RT-PCR) or in sit hybridization (ISH) or microarray. Cut-off values of high or low miRs expression were mainly mean and median values. As for clinical endpoints, there were 46 studies [1, 2, 10-12, $16,20,22,24-27,29-33,36-41,43-59,61-66]$ including overall survival (OS), 5 studies [67-71] including disease free survival (DFS) and another 9 studies [18, 19, 21, 23, $28,34,35,42,60]$ including both OS and DFS. We have identified a total of 59 miRs including 23 significantly up-regulated expression miRs (miR-214, miR-17, miR20a, miR-200c, miR-107, miR-27a, miR-196b, miR-222, miR-106b, miR-500, miR-377, miR-25, miR-181a, miR183, miR-1288, miR-106a-5p, miR-21, miR-30e, miR142-3p, miR-1246, miR-508, miR-503, miR-942) and 36 significantly down-regulated expression miRs (miR433, let-7g, miR-125a-5p, miR-760, miR-206, miR-26a, miR-200b, miR-185, miR-22, miR-217, miR-506, miR-
133, miR-218, miR-137, miR-326, miR-486-5p, miR-29, miR-23b-3p, miR-194, miR-451, miR-34a, miR-106a, miR-143, miR-16, miR-139-3p, miR-361-5p, miR-365, miR-338-3p, miR-200c, miR-141, miR-150, miR-138, miR-134a, miR-195 , miR-203, miR-375) correlated with poor prognosis in GIC patients (Table 1, Table 2). Moreover, 35 of them revealed mechanisms (Table 3).

\section{Meta-analysis findings}

We applied both random-effects and fixed-effects models to evaluate that the pooled hazard ratio (HR) value $(95 \% \mathrm{CI})$ of OS was $2.32(1.77-3.05)$ related to expression level of miR-21 in GIC patients with low heterogeneity $(P$ $\left.=0.54, I^{2}=0 \%\right)$ and statistically significance $(P<0.00001)$ after excluded one study [16, 24-27] (Figure 2). For all included studies, pooled HR values $(95 \% \mathrm{CI})$ of OS related to different miRs expression in $\mathrm{EC}, \mathrm{GC}, \mathrm{CRC}$ and

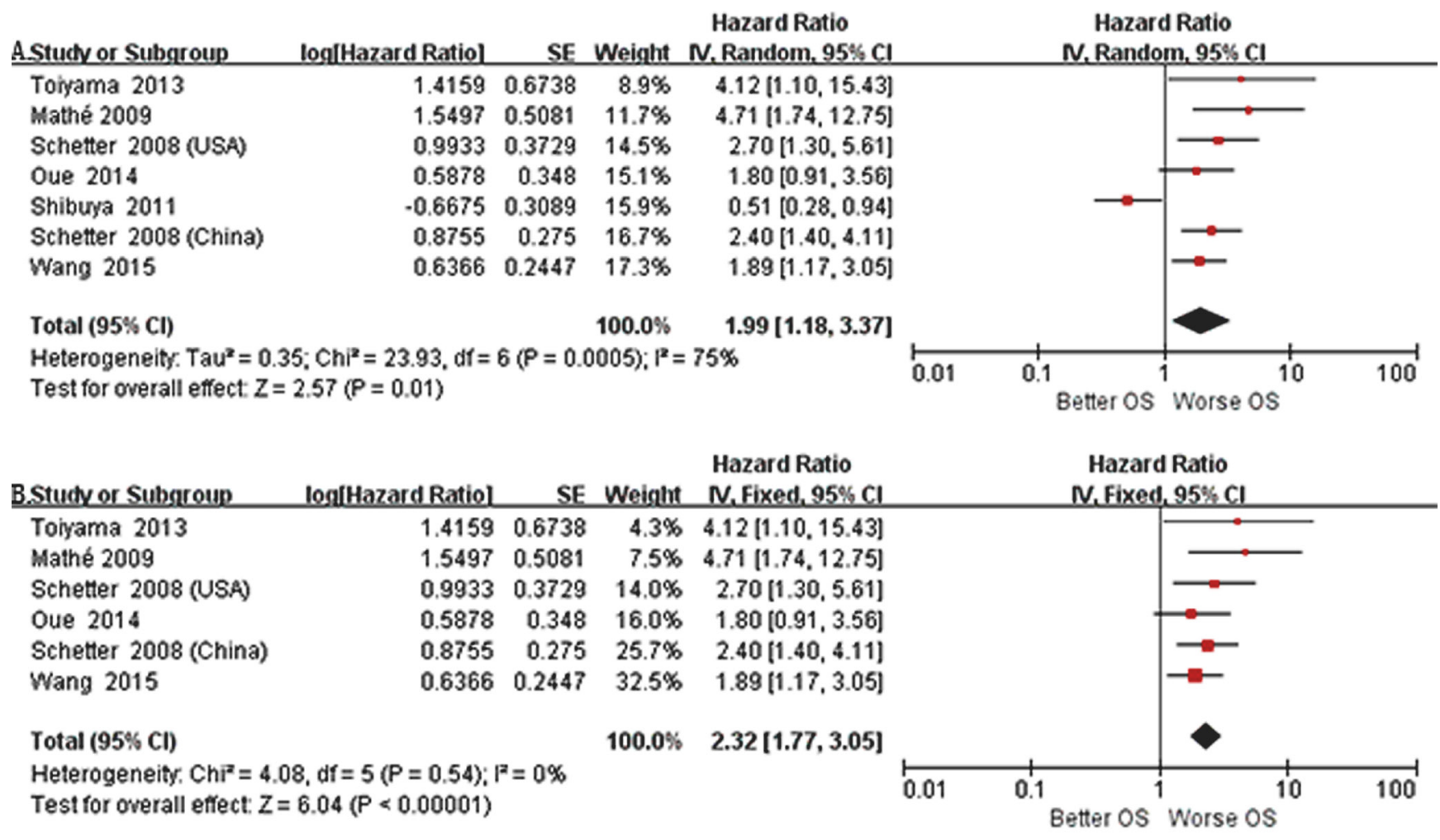

Figure 2: We performed forest plot to evaluate that the pooled hazard ratio value $(95 \% \mathrm{CI})$ of overall survival related to expression level of miR-21 in gastrointestinal cancer patients. A. Random-effects model, B. Fixed-effects model. 
Table 2: Characteristics of studies and different miRs expression related to DFS in GIC patients

\begin{tabular}{|c|c|c|c|c|c|c|c|c|c|c|}
\hline \multirow{2}{*}{ References } & \multirow{2}{*}{ Year } & \multirow{2}{*}{$\begin{array}{c}\text { MiRNAs } \\
(n=15)\end{array}$} & \multirow{2}{*}{ Nations } & \multirow{2}{*}{\begin{tabular}{|l} 
Number \\
$(n=1373)$ \\
\end{tabular}} & \multicolumn{2}{|r|}{ DFS } & \multirow{2}{*}{\begin{tabular}{|c|}
$\begin{array}{c}\text { Cut- } \\
\text { off }\end{array}$ \\
value \\
\end{tabular}} & \multirow{2}{*}{$\begin{array}{l}\text { Detection } \\
\text { methods } \\
\end{array}$} & \multirow{2}{*}{\begin{tabular}{|c|} 
Sample \\
types
\end{tabular}} & \multirow{2}{*}{\begin{tabular}{|c|} 
Follow \\
up
\end{tabular}} \\
\hline & & & & & HR* & $95 \% \mathrm{CI}$ & & & & \\
\hline \#Diaz [60] & 2008 & miR-106a $\downarrow$ & Spain & CRC 110 & 2.80 & $1.30-60$ & median & RT-PCR & tissue & $68-99$ \\
\hline Nguyen [67] & 2010 & miR-375 & USA & EC 58 & $2.73 *$ & $1.17-6.39$ & median & RT-PCR & tissue & $<80$ \\
\hline$\# \mathrm{Hu}[28]$ & 2011 & $\mathrm{miR}-30 \mathrm{e} \uparrow$ & China & EC 158 & 1.67 & \begin{tabular}{|l|}
$1.17-2.38$ \\
\end{tabular} & median & RT-PCR & tissue & $1-256$ \\
\hline $\begin{array}{l}\text { \#Ayerbes } \\
{[18]}\end{array}$ & 2012 & $\operatorname{miR}-200 \mathrm{c} \uparrow$ & Spain & GC 52 & $2.27 *$ & $1.09-4.71$ & mean & RT-PCR & blood & $6-53$ \\
\hline \#Inoue [23] & 2012 & 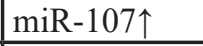 & Japan & GC 161 & $0.14 *$ & $0.01-0.67$ & mean & RT-PCR & tissue & $6-72$ \\
\hline Nie [68] & 2012 & 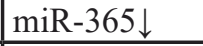 & China & CRC 76 & 1.84 & $0.80-4.22$ & mean & RT-PCR & tissue & $1-38$ \\
\hline \#Tang [42] & 2013 & miR-200b $\downarrow$ & China & GC 36 & 1.57 & $0.97-2.53$ & 2 fold & ISH & tissue & $23-59$ \\
\hline$\# \mathrm{Fu}[21]$ & 2014 & $\operatorname{miR}-222 \uparrow$ & China & GC 114 & $3.38 *$ & $1.87-5.23$ & median & RT-PCR & plasma & $18-60$ \\
\hline \#Lin [34] & 2014 & 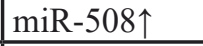 & China & EC 207 & 3.92 & $2.68-5.75$ & median & RT-PCR & tissue & $<60$ \\
\hline \#Sun [35] & 2014 & 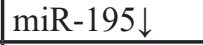 & China & EC 98 & 5.59 & 1.13-11.16 & median & RT-PCR & tissue & $1-63$ \\
\hline Sun [69] & 2014 & miR-338-3p $\downarrow$ & China & CRC 40 & 2.30 & \begin{tabular}{|l|}
$1.20-3.90$ \\
\end{tabular} & mean & RT-PCR & tissue & $1-72$ \\
\hline $\begin{array}{l}\text { \#Imaoka } \\
{[19]}\end{array}$ & 2015 & 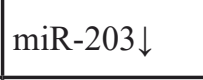 & Japan & GC 130 & 1.54 & $0.46-5.13$ & YI & RT-PCR & serum & $1-78$ \\
\hline \multirow[t]{2}{*}{ Zhou [70] } & 2015 & miR-200c $\downarrow$ & China & GC 63 & 1.38 & $0.70-2.72$ & median & RT-PCR & tissue & $28-33$ \\
\hline & & miR-141 $\downarrow$ & & & 1.20 & $0.58-2.46$ & median & RT-PCR & tissue & $28-33$ \\
\hline Yue [71] & 2015 & $\begin{array}{l}\text { miR-106a- } \\
5 \mathrm{p} \uparrow\end{array}$ & China & CRC 70 & 2.21 & $1.46-4.11$ & median & RT-PCR & tissue & $<80$ \\
\hline
\end{tabular}

\# = Studies included both OS and DFS; * = adjusted HR; $\uparrow$ or $\downarrow$ up-regulated or down-regulated with poor prognosis; GIC gastrointestinal cancer; EC esophageal cancer; GC gastric cancer; CRC colorectal cancer; OS overall survival; DFS disease free survival; HR hazard ratio; YI Youden index; RT-PCR reverse transcription PCR; ISH in sit hybridization; Calculated HR of DFS was in bold.

GIC patients were 2.10 (1.78-2.49), 2.02 (1.83-2.23), 2.54 (2.14-3.02) and $2.15(1.99-2.31)$, respectively. And there was low heterogeneity $\left(P=0.21, I^{2}=13 \%\right)$ and statistically significance $(P<0.00001)$ in GIC (Figure 3$)$. Additionally, pooled HR value $(95 \% \mathrm{CI})$ of DFS related to different miRs expression in GIC patients was 2.12 (1.72-2.61) with low heterogeneity $\left(P=0.04, I^{2}=43 \%\right)$ and statistically significance $(P<0.00001)$ (Figure 4$)$. Pooled HR value of OS related to circulatory miRs expression in GIC patients was 2.02 (1.63-2.49) (Supplementary Figure 1). Furthermore, miR-21 related meta-analysis was verified by Begg's test $(P=0.260)$ (Figure 5$)$.

\section{DISCUSSION}

Gastrointestinal cancer is still a deadly threat in human health due to tumor metastasis and relapse inducing refractory advanced tumor stage and poor prognosis. Yan et al. [72] have demonstrated that there was $40 \%-65 \%$ recurrence rate due to distant metastases and regional relapse in GC patients. Recently, numerous studies focused on the miRs as prognostic molecular biomarkers in GIC patients for precise prediction. For example, Kang et al. [73] reported that miR-21 can be an independent predictor for tumor relapse in CRC patients, and Xu et al. [74] demonstrated that miR-21 as a promising biomarker can predict the lymph node metastases of tumor in GC patients.
The pooled HR value of OS correlated with different miRs expression in GIC patients was 2.14 (1.98-2.30), which implied specific miRs as independent risks inducing poor prognosis and could be considered as prognostic indicators for clinical decision-making. OS was defined as the time interval between GIC confirmed and end of follow up [75]. Moreover, elevated miR-21 expression promoted the tumor cell growth, invasion and migration, and inhibited its apoptosis by targeted PTEN and TIMP1, which was associated with low overall survival. Therefore, miR-21 as a stable molecular biomarker can be used to predict the prognosis of GIC patients. Additionally, miR21 can also play a diagnostic role in GIC patients [76]. The pooled HR value of DFS associated with different miRs was 2.12 (1.72-2.61), which demonstrated different miRs leading to poor DFS and can be applied to monitor the therapeutic effects after receiving radical resection or chemotherapy. DFS was described as the time interval from GIC confirmed to relapse or end of follow up [68]. All included miRs were statistically significant associated with poor prognosis in GIC patients. Generally, the expression level of identical miR in GIC patients was consistent. For example, Yang et al. [2] reported that decreased miR-206 expression correlated with worse OS in GC patient and the finding was confirmed by Shi et al. [58]. While there were inversely results from different research institutions for identical miR associated prognosis of GIC patients. For instance, Ayerbes et al. [18] revealed 


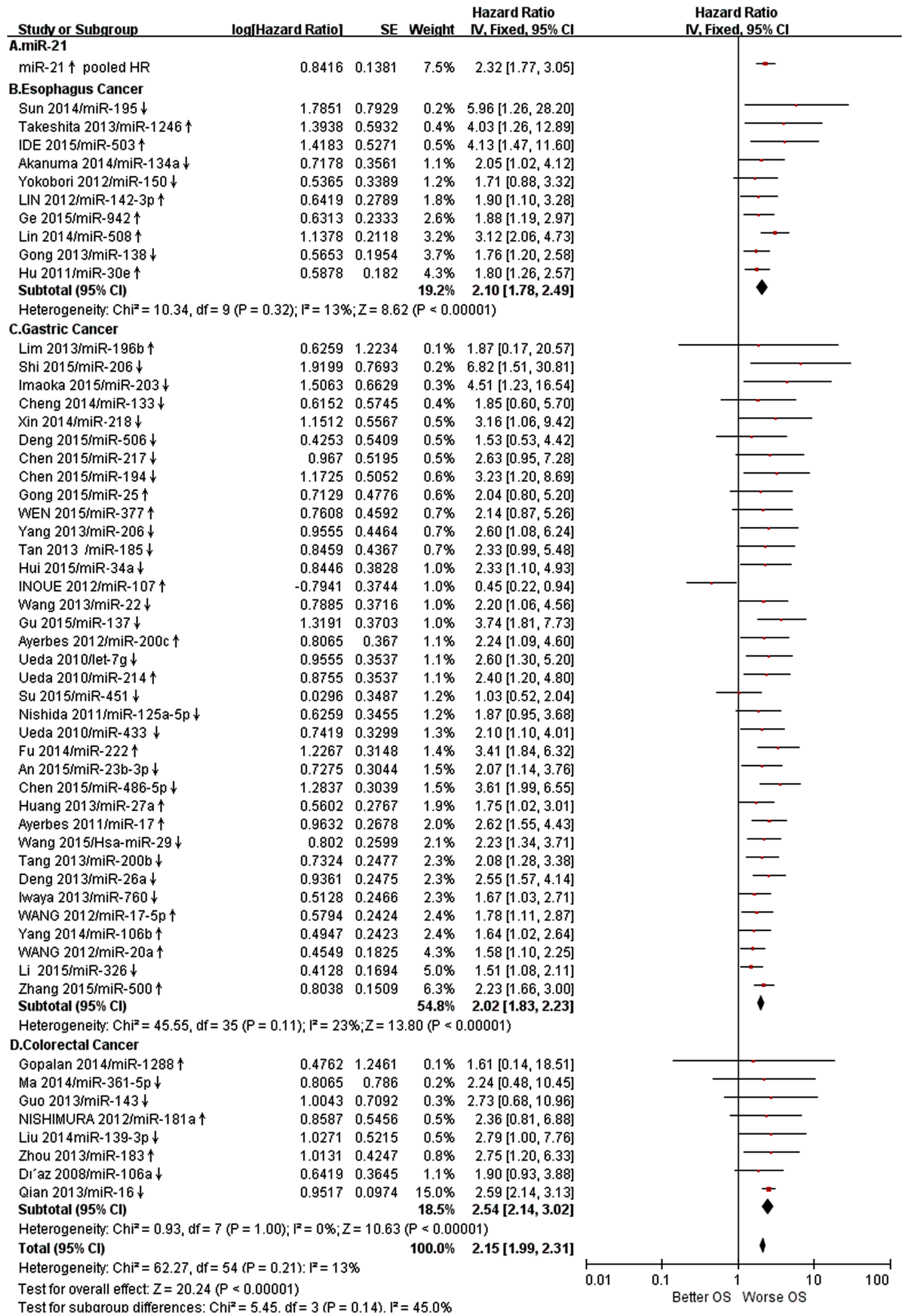

Figure 3: Forest plot of OS associated with expression level of different miRs in GIC patients was presented. A. Pooled miR-21 expression in GIC, B. Specific miRs expression in EC, C. Specific miRs expression in GC, D. Specific miRs expression in CRC. OS overall survival; GIC gastrointestinal cancer; EC esophageal cancer; GC gastric cancer; CRC colorectal cancer. 
Table 3: miRs and target genes in gastrointestinal cancer

\begin{tabular}{|c|c|c|c|c|c|}
\hline $\operatorname{MiRs}(\mathrm{n}=35)$ & Poor prognosis & Role & Target genes & Function & Reference \\
\hline $\operatorname{miR}-21 \uparrow$ & Up-regulation & oncogene & PTEN, TIMP1 & $\begin{array}{l}\text { growth/invasion/migration/ } \\
\text { apoptosis }\end{array}$ & {$[16,24-27]$} \\
\hline $\operatorname{miR}-107 \uparrow$ & Up-regulation & oncogene & DICER1 & invasion/migration & {$[23]$} \\
\hline $\operatorname{miR}-377 \uparrow$ & Up-regulation & oncogene & P53, PTEN , TIMP1 & proliferation & {$[10]$} \\
\hline $\operatorname{miR}-25 \uparrow$ & Up-regulation & oncogene & FBXW7 & growth/invasion/migration & {$[55]$} \\
\hline $\operatorname{miR}-106 \mathrm{~b} \uparrow$ & Up-regulation & oncogene & PTEN & invasion/migration & [47] \\
\hline miR-500个 & Up-regulation & oncogene & NF-кB & proliferation/apoptosis & {$[51]$} \\
\hline $\operatorname{miR}-181 \mathrm{a} \uparrow$ & Up-regulation & oncogene & PTEN & proliferation & {$[61]$} \\
\hline $\mathrm{miR}-183 \uparrow$ & Up-regulation & oncogene & PTEN & migration & {$[62]$} \\
\hline 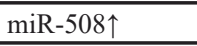 & Up-regulation & oncogene & INPP5J & growth/invasion/migration & {$[34]$} \\
\hline $\operatorname{miR}-942 \uparrow$ & Up-regulation & oncogene & sFRP4, GSK3 $\beta$, TLE1 & growth & {$[37]$} \\
\hline $\operatorname{miR}-1288 \uparrow$ & Up-regulation & oncogene & FOXO1 & proliferation & {$[66]$} \\
\hline 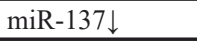 & Down-regulation & suppressor & AKT2 & growth & {$[22]$} \\
\hline miR-138 $\downarrow$ & Down-regulation & suppressor & NF-kB & growth & {$[31]$} \\
\hline miR-760 & Down-regulation & suppressor & HIST1H3D & migration & [40] \\
\hline 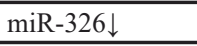 & Down-regulation & suppressor & FSCN1 & growth/migration & [53] \\
\hline miR-125a-5p $\downarrow$ & Down-regulation & suppressor & ERBB2 & growth & {$[39]$} \\
\hline miR-134a $\downarrow$ & Down-regulation & suppressor & FSCN, MMP14 & invasion/migration & {$[33]$} \\
\hline 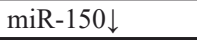 & Down-regulation & suppressor & ZEB1 & EMT & {$[30]$} \\
\hline 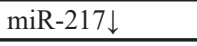 & Down-regulation & suppressor & EZH2 & progression/metastasis & [48] \\
\hline miR-506 $\downarrow$ & Down-regulation & suppressor & Yap1 & proliferation/invasion & {$[52]$} \\
\hline $\operatorname{miR}-26 \mathrm{a} \downarrow$ & Down-regulation & suppressor & FGF9 & growth/metastasis & {$[41]$} \\
\hline miR-200b $\downarrow$ & Down-regulation & suppressor & DNMT3A/3B, SP1 & growth & {$[42]$} \\
\hline $\operatorname{miR}-23 b-3 p \downarrow$ & Down-regulation & suppressor & ATG12, HMGB2 & chemoresistance & {$[12]$} \\
\hline 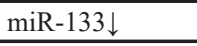 & Down-regulation & suppressor & CDC42-PAK & growth/migration/invasion & [48] \\
\hline 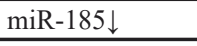 & Down-regulation & suppressor & DNMT1, CDC42 & metastasis & [43] \\
\hline 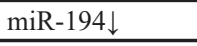 & Down-regulation & suppressor & RBX1 & proliferation/migration & {$[56]$} \\
\hline miR-218 $\downarrow$ & Down-regulation & suppressor & Robo1 & growth/invasion/apoptosis & [49] \\
\hline miR-200c/141 $\downarrow$ & Down-regulation & suppressor & ZEB1/2 & migration/ invasion & {$[70]$} \\
\hline 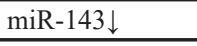 & Down-regulation & suppressor & TLR2 & invasion/migration & {$[11]$} \\
\hline miR-106a $\downarrow$ & Down-regulation & suppressor & EGFL7, E2F1 & invasion/migration & [60] \\
\hline 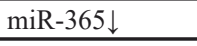 & Down-regulation & suppressor & Cyclin D1, Bcl-2 & apoptosis & {$[68]$} \\
\hline miR-16 $\downarrow$ & Down-regulation & suppressor & P53 & growth & {$[64]$} \\
\hline $\operatorname{miR}-338-3 p \downarrow$ & Down-regulation & suppressor & SMO & apoptosis & [69] \\
\hline $\operatorname{miR}-203 \downarrow$ & Down-regulation & suppressor & E-cadherin & EMT/migration & [19] \\
\hline
\end{tabular}

that highly expressed miR-200c induced poor DFS in GC patients. Conversely, zhou et al. [70] demonstrated that low expression of miR-200c leaded to worse DFS in GC patients. Usually, evaluating prognosis of patients is inextricably bound to clinical decision-making. And researching signal pathways and target genes of miRs may promote the development of novel drug target therapies. Therefore, we summarized the miRs mechanism research associated with prognosis of GIC patients. We found 35 miRs associated with prognosis of GIC patients had explicit targets and some of them have established animal models but further study on clinical trials is required.

Based on this meta-analysis, we can preliminarily draw the clinical value of multiple miRs correlated with prognosis of GIC patients. (1) Aberrant expression of different miRs was associated with the survival of patients and miR-21 as a stable molecular biomarker can predict the individual prognosis through detecting its expression levels in GIC patients. (2) MiRs can offer more precise information for clinical decision-making comparing with the clinicopathological characteristics (such as tumor grade and size) of GIC patients. (3) Expression levels of specific miRs can be detected in tumor tissues or blood samples, which can be used to monitor the therapeutic effects of GIC patients after receiving chemotherapy treatment. (4) Abnormal miRs expression may provide a clinically valuable application for identifying patients with high risk at early stage avoiding advanced cancer progression. (5) It also provides a potential value for clinical decision-making development and may serve as a promising miR-based target therapy waiting for further elucidation.

However, several limitations deserved focused. First, both detection methods (RT-PCR, ISH and microarray) and cut-off values (mean, median, etc.) were applied to evaluate the different miRs expression that may be the source of heterogeneity due to different algorithms. Second, several sample types (tissue, blood, serum, plasma 
and bone marrow) were researched by all included studies can also induce the heterogeneity. Quantifiable miRs can be obtained from tissue samples because of its endogenous expression and mostly used to predict the patient survival after receiving resection treatment. Circulatory miRs as noninvasive biomarkers were more likely to predict the prognosis of GIC patients at unresectable stage and surveille the treatment effects of receiving chemotherapy for long term follow up study when compared with tissue samples. Third, clinicopathology characteristics (American Joint Committee on Cancer stage, AJCC stage) associated with prognosis of GIC patients could be the confounding factors inducing high heterogeneity. Therefore, we merely included studies that were focusing on the full sages (IIV) rather than one certain stage GIC research. Fourth, we extracted HR and 95\% CI values from Kaplan-Meier curve according to Tierney's methodology because there were 21 studies lack of survival data, which may cause potential heterogeneity [77]. Fifth, more than half included studies that did not report the adjusted HR values were prone to high heterogeneity. As for publication bias, failure to publish negative results of articles leading to overestimate the pooled effect value, which have reached a consensus. Besides, language bias was existed because only English publications were enrolled in this study. Thus, we systematically searched a wide range of database and found there was no publication bias in all analysis except miR-21 related meta-analysis. After excluding one study in miR-21 related meta-analysis for sensitivity analysis, the pooled effect value did not substantially change implying high stability.

\section{CONCLUSIONS}

Overall, specific miRs are significantly associated with the prognosis of GIC patients and potentially eligible for the prediction of patients survival. It also provides a potential value for clinical decision-making development

\begin{tabular}{|c|c|c|c|c|c|c|c|c|}
\hline Studv or Subgroup & loglHazard Ratio] & SE & Weight & $\begin{array}{l}\text { Hazard Ratio } \\
\text { N. Random, } 95 \% \mathrm{Cl}\end{array}$ & \multicolumn{4}{|c|}{$\begin{array}{c}\text { Hazard Ratio } \\
\text { IV. Random, } 95 \% \mathrm{Cl}\end{array}$} \\
\hline \multicolumn{9}{|l|}{ A.Esophagus Cancer } \\
\hline Sun 2014/miR-195 $\downarrow$ & 1.721 & 0.8157 & $1.6 \%$ & $5.59[1.13,27.65]$ & & & & \\
\hline Nguyen $2010 / \mathrm{miR}-375 \downarrow$ & 1.0043 & 0.4323 & $4.5 \%$ & $2.73[1.17,6.37]$ & & & & \\
\hline Lin $2014 / \mathrm{miR}-508 \uparrow$ & 1.3661 & 0.194 & $10.8 \%$ & $3.92[2.68,5.73]$ & & & & \\
\hline Hu $2011 / \mathrm{miR}-30 \mathrm{e} \uparrow$ & 0.5128 & 0.1815 & $11.2 \%$ & $1.67[1.17,2.38]$ & & & & \\
\hline Subtotal $(95 \% \mathrm{Cl})$ & & & $\mathbf{2 8 . 0} \%$ & $2.80[1.57,4.99]$ & & & & \\
\hline \multicolumn{9}{|c|}{$\begin{array}{l}\text { Heterogeneity: } \mathrm{Tau}^{2}=0.22 ; \mathrm{Chi}^{2}=11.30, \mathrm{df}=3(\mathrm{P}=0.01) ; \mathrm{I}^{2}=73 \% \\
\text { Test for overall effect: } Z=3.48(P=0.0005)\end{array}$} \\
\hline \multicolumn{9}{|l|}{ B.Gastric Cancer } \\
\hline INOUE $2012 / \mathrm{miR}-107 \uparrow$ & -1.9733 & 1.4567 & $0.5 \%$ & $0.14[0.01,2.42]$ & & & & \\
\hline Imaoka $2015 / \mathrm{miR}-203 \downarrow$ & 0.4318 & 0.6165 & $2.6 \%$ & $1.54[0.46,5.16]$ & & & & \\
\hline Ayerbes 2012 /miR-200c $\uparrow$ & 0.8198 & 0.3729 & $5.5 \%$ & $2.27[1.09,4.71]$ & & & & \\
\hline Zhou $2015 / \mathrm{miR}-141 \downarrow$ & 0.1823 & 0.371 & $5.6 \%$ & $1.20[0.58,2.48]$ & & & & \\
\hline Zhou $2015 / \mathrm{miR}-200 \mathrm{c} \downarrow$ & 0.3221 & 0.3463 & $6.1 \%$ & $1.38[0.70,2.72]$ & & & & \\
\hline Fu $2014 / \mathrm{miR}-222 \uparrow$ & 1.2179 & 0.302 & $7.2 \%$ & $3.38[1.87,6.11]$ & & & & \\
\hline Tang $2013 / \mathrm{miR}-200 \mathrm{~b} \downarrow$ & 0.4511 & 0.2457 & $8.9 \%$ & $1.57[0.97,2.54]$ & & & & \\
\hline Tang $2013 / \mathrm{miR}-200 \mathrm{c} \downarrow$ & 0.5988 & 0.2298 & $9.4 \%$ & $1.82[1.16,2.86]$ & & & & \\
\hline Subtotal $(95 \% \mathrm{Cl})$ & & & $45.7 \%$ & $1.77[1.32,2.37]$ & & & & \\
\hline \multicolumn{9}{|c|}{$\begin{array}{l}\text { Heterogeneity: } \text { Tau }^{2}=0.05 ; \mathrm{Chi}^{2}=9.99, \mathrm{df}=7(P=0.19) ; \mathrm{I}^{2}=30 \% \\
\text { Test for overall effect: } Z=3.84(P=0.0001)\end{array}$} \\
\hline \multicolumn{8}{|l|}{ C.Colorectal Cancer } & \\
\hline Nie $2012 / \mathrm{miR}-365 \downarrow$ & 0.6098 & 0.425 & $4.6 \%$ & $1.84[0.80,4.23]$ & & & & \\
\hline DI'az 2008/miR-106a $\downarrow$ & 1.0296 & 0.3915 & $5.2 \%$ & $2.80[1.30,6.03]$ & & & & \\
\hline Sun $2014 / \mathrm{miR}-338-3 p \downarrow$ & 0.8329 & 0.3319 & $6.4 \%$ & $2.30[1.20,4.41]$ & & & & \\
\hline Yue $2015 / \mathrm{miR}-106 a-5 p \uparrow$ & 0.793 & 0.2115 & $10.1 \%$ & $2.21[1.46,3.35]$ & & & & \\
\hline Subtotal $(95 \% \mathrm{Cl})$ & & & $26.3 \%$ & $2.26[1.68,3.04]$ & & & & \\
\hline \multicolumn{9}{|c|}{$\begin{array}{l}\text { Heterogeneity: } \operatorname{Tau}^{2}=0.00 ; \mathrm{Chi}^{2}=0.55, \mathrm{df}=3(\mathrm{P}=0.91) ; \mathrm{F}^{2}=0 \% \\
\text { Test for overall effect: } Z=5.37(\mathrm{P}<0.00001)\end{array}$} \\
\hline Total $(95 \% \mathrm{Cl})$ & & & $100.0 \%$ & $2.12[1.72,2.61]$ & & & & \\
\hline $\begin{array}{l}\text { Heterogeneity: } \text { Tau }^{2}=0.07 \\
\text { Test for overall effect: } Z=7 \\
\text { Test for subaroun differen }\end{array}$ & $\begin{array}{l}h i^{2}=26.21, d f=15( \\
(P=0.00001) \\
: C h i^{2}=2.44 . d f=2\end{array}$ & $\begin{array}{l}(P=0.04) \\
(P=0.29\end{array}$ & $i^{2}=43 \%$ & & 0.01 & 0.1 Better DFS & Worse DFS & 100 \\
\hline
\end{tabular}

Figure 4: Forest plot of DFS associated with expression level of specific miRs in GIC patients was presented. A. Specific miRs expression in EC, B. Specific miRs expression in GC, C. Specific miRs expression in CRC. DFS disease free survival; GIC gastrointestinal cancer; EC esophageal cancer; GC gastric cancer; CRC colorectal cancer. 
and may serve as a promising miR-based target therapy waiting for further elucidation.

\section{MATERIALS AND METHODS}

\section{Search strategy}

We searched a wide range of database (PubMed, Web of Science and EMBASE) for published English articles, and additional records identified through other sources such as contacting authors and searching unpublished studies up to August 1, 2016. Search terms were consisted of "microRNA", "miRNA", "miR", "cancer", "tumor", "malignant", "metastasis", "carcinoma", "gastrointestine", "gastroenteric", "esophagus", "esophageal", "gastric", "stomach", "colon", "rectum", "colonrectum", "incidence", "mortality", "follow up studies", "prognosis", "prediction", "survival", "hazard ratio", and combined with AND/OR.

\section{Selection criteria}

Two reviewers read the studies intensively and evaluated the eligibility of studies independently based on selection criteria involving inclusion criteria: (1) Patients were diagnosed with gastrointestinal cancer by histopathology; (2) MiRs as prognostic markers were used to predict the prognosis for full stage (I-IV) patients. (3) Control group (healthy people or patients without GIC) was contained; (4) The effective outcomes were OS, DFS, HR and 95\% CI; (5) Observational studies that we can extract the survival data from the articles or Kaplan-Meier survival curve were included; and exclusion criteria: (1) Non-English and non-human subject studies were excluded; (2) Studies were letters, reviews and reports lack of survival data; (3) Studies focused on genetic alterations about the polymorphisms or modification of miRs. We would get to consensus finally through discussion when disagreements came out.

\section{Data extraction and quality assessment}

We collected specific information (the first author, year of publication, nation, number of patients, OS/DFS HR and $95 \%$ CI, cut-off value, detection method, sample type and follow up) from each included study. The quality of included studies was assessed according to the checklist of meta-analysis of observational studies in epidemiology (MOOSE) [78]:

Explicit definition of study population exposure.
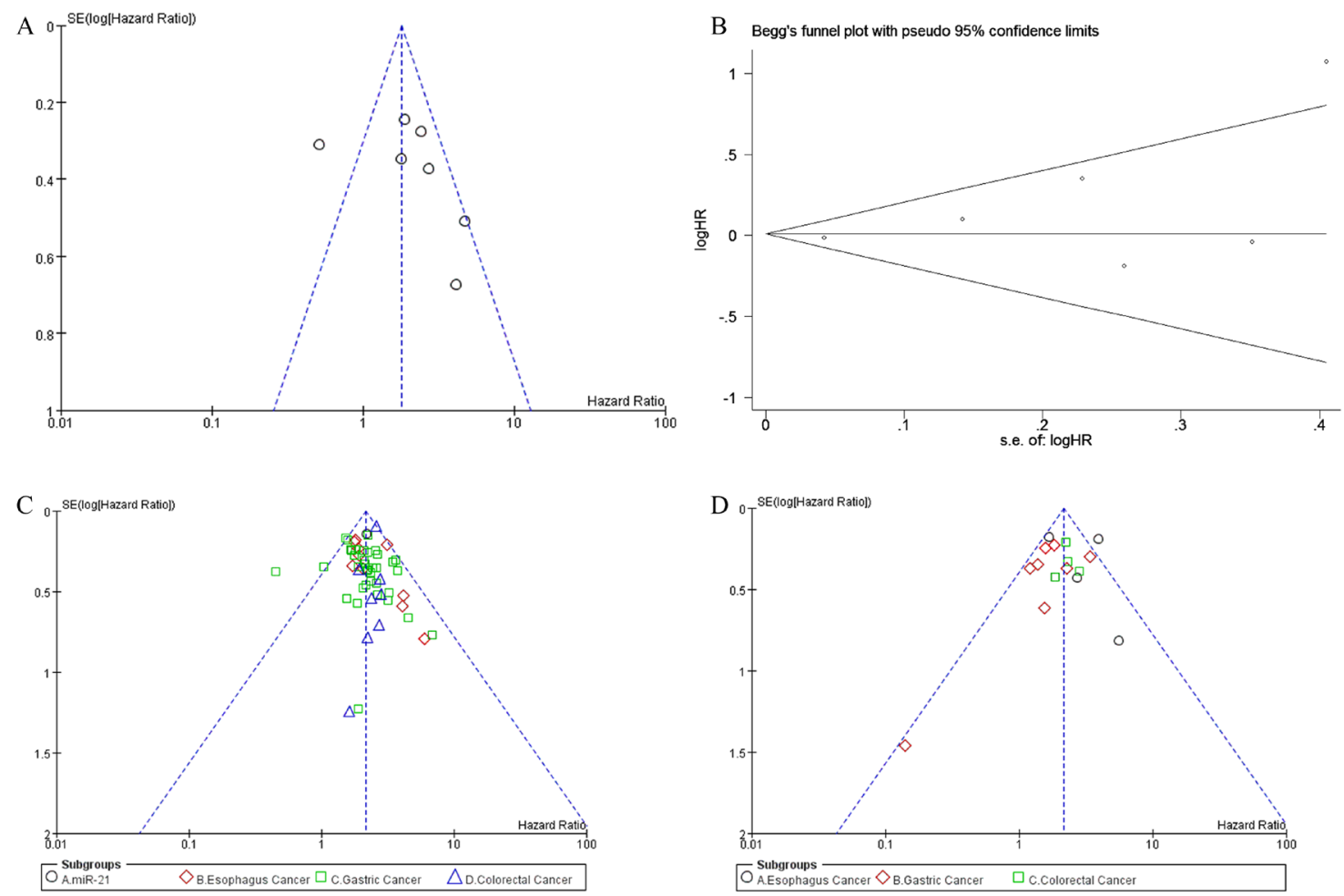

Figure 5: Funnel plots of included studies in this meta-analysis. A. highly expressed miR-21 correlated with OS in GIC patients, B. highly expressed miR-21 correlated with OS in GIC patients was verified by Begg's test, C. Aberrantly expressed miRs correlated with OS in GIC patients, D. Aberrantly expressed miRs correlated with DFS in GIC patients. OS overall survival; DFS disease free survival; GIC gastrointestinal cancer. 
Explicit definition of measurement of miRs expression such as qRT-PCR, ISH and microarray.

Explicit definition of outcomes (OS and DFS).

Explicit definition of cut-off value and follow-up.

Explicit definition of study design.

\section{Statistical analysis}

Analysis was implemented by Review Manager 5.3 (The Nordic Cochrane Centre, The Cochrane Collaboration, London, UK) and Stata 12.0 (Stata Corporation, College Station, Texas, USA) software. We applied both fixed-effects and random-effects models to evaluate the pooled value of HR by calculating Cochran $\mathrm{Q}$ test and $I^{2}$ Index values. If $P>0.10$ and $I^{2}<50 \%$ implied that low heterogeneity of pooled HR value is statistically significant difference, fixed-effects model should be used finally. Otherwise, random-effects model would be performed. In addition, forest plots of pooled HR values were presented. Funnel plots were used to qualitatively analyze the publication bias and verified by Begg's test while it seems asymmetry. Moreover, we also conducted sensitivity analysis for this meta-analysis.

\section{ACKNOWLEDGMENTS}

Thanks for the authors of all included studies.

\section{CONFLICTS OF INTEREST}

The authors declare that they have no conflict of interest.

\section{GRANT SUPPORT}

This work was granted from Science and Technology Project of Anhui (3101005002598).

\section{REFERENCES}

1. Valladares-Ayerbes M, Blanco M, Haz M, Medina V, Iglesias-Díaz P, Lorenzo-Patino MJ, Reboredo M, Santamarina I, Figueroa A, Antón-Aparicio L, Calvo L. Prognostic impact of disseminated tumor cells and microRNA-17-92 cluster deregulation in gastrointestinal cancer. Int J Oncol. 2011; 1-11.

2. Yang Q, Zhang C, Huang B, Li H, Zhang R, Huang Y, Wang JJ. Downregulation of microRNA-206 is a potent prognostic marker for patients with gastric cancer. Eur J Gastroenterol Hepatol. 2013; 25:953-957.

3. Song S, Ajani JA. The role of microRNAs in cancers of the upper gastrointestinal tract. Nat Rev Gastroenterol Hepatol. 2013; 10:1-23.

4. Zhang L, Xia L, Zhao L, Xia LM, Zhao LN, Chen ZQ,
Shang X, Xin J, Liu MH, Guo XG, Wu KC, Pan VL, Fan DM. Activation of PAX3-MET pathways due to miR-206 loss promotes gastric cancer metastasis. Carcinogenesis. 2015; 36:390-399.

5. Pichler M, Winter E, Stotz M, Eberhard K, Samonigg H, Lax S, Hoefler G. Down-regulation of KRAS-interacting miRNA-143 predicts poor prognosis but not response to EGFR-targeted agents in colorectal cancer. $\mathrm{Br} \mathrm{J}$ Cancer. 2012; 106:1826-1832.

6. Zhai H, Fesler H, Ba Y, Wu S, Ju J. Inhibition of colorectal cancer stem cell survival and invasive potential by hsa-miR-140-5p mediated suppression of Smad2 and autophagy. Oncotarget. 2015; 6:19735-46. doi: 10.18632/ oncotarget.3771.

7. Kozomara A, Griffiths-Jones S. miRBase: integrating microRNA annotation and deep-sequencing data. Nucleic Acids Res. 2011; 39:D152-D157.

8. Slattery ML, Herrick JS, Mullany LE, Valeri N, Stevens J, Caan BJ, Samowitz W, Wolff RK. An evaluation and replication of miRNAs with disease stage and colorectal cancer-specific mortality. Int J Cancer. 2015; 137:428-438.

9. Mu YP, Tang S, Sun WJ, Gao WM, Wang M, Su XL. Association of miR-193b Down-regulation and miR196a up-Regulation with Clinicopathological Features and Prognosis in Gastric Cancer. Asian Pacific Journal of Cancer Prevention. 2014; 15:8893-8900.

10. Wen X, Wu JQ, Peng W, Feng JF, Tang JH. MicroRNA-377 predicts poor clinical outcome of gastric cancer and induces tumorigenesis by targeting multiple tumor-suppressor genes. Oncol Rep. 2015; 201-210.

11. Guo H, Chen Y, Hu X, Qian G, Ge S, Zhang J. The regulation of Toll-like receptor 2 by miR-143 suppresses the invasion and migration of a subset of human colorectal carcinoma cells. Mol Cancer. 2013; 12:77-87.

12. An Y, Zhang Z, Shang Y, Jiang X, Dong J, Yu P, Nie Y, Zhao Q. MiR-23b-3p regulates the chemoresistance of gastric cancer cells by targeting ATG12 and HMGB2. Cell Death Dis. 2015; 6:e1766.

13. Pink RC, Samuel P, Massa D, Caley DP, Brooks SA, Carter DRF. The passenger strand, miR-21-3p, plays a role in mediating cisplatin resistance in ovarian cancer cells. Gynecol Oncol. 2015; 143-151.

14. Yadav P, Mirza M, Nandi K, Jain SK, Kaza RCM, Khurana N, Ray PC, Saxena A. Serum microRNA-21 expression as a prognostic and therapeutic biomarker for breast cancer patients. Tumour Biol. 2016; 1-8.

15. Ilhan-Mutlu A, Tezcan G, Schoppmann SF, Preusser M, Spyridoula K, Karanikas G, Birner P. MicroRNA-21 expression is elevated in esophageal adenocarcinoma after neoadjuvant chemotherapy. Cancer Invest. 2015; 1-5.

16. Wang D, Fan Z, Liu F, Zuo J. Hsa-miR-21 and HsamiR-29 in Tissue as Potential Diagnostic and Prognostic Biomarkers for Gastric Cancer. Cell Physiol Biochem. 2015; 37:1454-1462. 
17. Shibuya H, Iinuma H, Shimada R, Horiuchi A, Watanabe T. Clinicopathological and prognostic value of microRNA-21 and microRNA-155 in colorectal cancer. Oncology. 2010; 79:313-320.

18. Valladares-Ayerbes M, Reboredo M, Medina-Villaamil V, Iglesias-Díaz P, Lorenzo-Patiño MJ, Haz M, Santamarina I, Blanco M, Fernández-Tajes J, Quindós M, Carral A, Figueroa A, Antón-Aparicio LM, et al. Circulating miR$200 \mathrm{c}$ as a diagnostic and prognostic biomarker for gastric cancer. J Transl Med. 2012; 10:186.

19. Imaoka H, Toiyama Y, Okigami M, Yasuda M, Saigusa S, Ohi M, Tanaka K, Inoue Y, Mohri Y, Kusunoki M. Circulating microRNA-203 predicts metastases, early recurrence, and poor prognosis in human gastric cancer. Gastric Cancer. 2016; 1-10.

20. Wang M, Gu H, Wang S, Qian H, Zhu W, Zhang L, Zhao C, Tao Y, Xu W. Circulating miR-17-5p and miR-20a: molecular markers for gastric cancer. Mol Med Rep. 2012; 5:1514-1520.

21. Fu Z, Qian F, Yang X, Jiang H, Chen Y, Liu S. Circulating miR-222 in plasma and its potential diagnostic and prognostic value in gastric cancer. Med Oncol. 2014; $31: 164$.

22. Gu Q, Zhang J, Hu H, Tan Y, Shi S, Nian Y. Clinical Significance of MiR-137 Expression in Patients with Gastric Cancer After Radical Gastrectomy. PLoS One. 2015; 10:e0142377.

23. Inoue $T$, Iinuma $H$, Ogawa $E$, Inaba $T$, Fukushima $R$. Clinicopathological and prognostic significance of microRNA-107 and its relationship to DICER1 mRNA expression in gastric cancer. Oncol Rep. 2012; 27:17591764.

24. Schetter AJ, Leung SY, Sohn JJ, Zanetti KA, Bowman ED, Yanaihara N, Yuen ST, Chan TL, Kwong DL, Au GK, Liu CG, Calin GA, Croce CM, Harris CC. MicroRNA expression profiles associated with prognosis and therapeutic outcome in colon adenocarcinoma. JAMA. 2008; 299:425-436.

25. Mathé EA, Nguyen GH, Bowman ED, Zhao Y, Budhu A, Schetter AJ, Braun R, Reimers M, Kumamoto K, Hughes D, Altorki NK, Casson AG, Liu CG, et al. MicroRNA expression in squamous cell carcinoma and adenocarcinoma of the esophagus: associations with survival. Clinical cancer research. 2009; 15:6192-6200.

26. Toiyama Y, Takahashi M, Hur K, Nagasaka T, Tanaka $\mathrm{K}$, Inoue $\mathrm{Y}$, Kusunoki M, Richard Boland C, Goel A. Serum miR-21 as a diagnostic and prognostic biomarker in colorectal cancer. J Natl Cancer Inst. 2013; 105:849-859.

27. Oue N, Anami K, Schetter AJ, Moehler M, Okayama H, Khan MA, Bowman ED, Mueller A, Schad A, Shimomura M, Hinoi T, Aoyagi K, Sasaki H, et al. High miR-21 expression from FFPE tissues is associated with poor survival and response to adjuvant chemotherapy in colon cancer. Int J Cancer. 2014; 134:1926-1934.
28. Hu Y, Correa AM, Hoque A, Guan B, Ye F, Huang J, Swisher SG, Wu TT, Ajani JA, Xu X. Prognostic significance of differentially expressed miRNAs in esophageal cancer. International journal of cancer. 2011; 128:132-143.

29. Lin RJ, Xiao DW, Liao LD, Chen T, Xie ZF, Huang WZ, Wang WS, Jiang TF, Wu BL, Li EM, Xu LY. MiR-142$3 p$ as a potential prognostic biomarker for esophageal squamous cell carcinoma. Journal of surgical oncology. 2012; 105:175-182.

30. Yokobori T, Suzuki S, Tanaka N, Inose T, Sohda M, Sano A, Sakai M, Nakajima M, Miyazaki T, Kato H, Kuwano H. MiR-150 is associated with poor prognosis in esophageal squamous cell carcinoma via targeting the EMT inducer ZEB1. Cancer science. 2013; 104:48-54.

31. Gong H, Song L, Lin C, Liu A, Lin X, Wu J, Li M, Li J. Downregulation of miR-138 sustains NF- $\kappa$ B activation and promotes lipid raft formation in esophageal squamous cell carcinoma. Clin Cancer Res. 2013; 19:1083-1093.

32. Takeshita N, Hoshino I, Mori M, Akutsu Y, Hanari $\mathrm{N}$, Yoneyama $\mathrm{Y}$, Ikeda $\mathrm{N}$, Isozaki $\mathrm{Y}$, Maruyama $\mathrm{T}$, Akanuma N, Komatsu A, Jitsukawa M, Matsubara H. Serum microRNA expression profile: miR-1246 as a novel diagnostic and prognostic biomarker for oesophageal squamous cell carcinoma. British journal of cancer. 2013; 108:644-652.

33. Akanuma N, Hoshino I, Akutsu Y, Murakami K, Isozaki Y, Maruyama T, Yusup G, Qin W, Toyozumi T, Takahashi M, Suito H, Hu X, Sekino N, et al. MicroRNA-133a regulates the mRNAs of two invadopodia-related proteins, FSCN1 and MMP14, in esophageal cancer. British journal of cancer. 2014; 110:189-198.

34. Lin C, Liu A, Zhu J, Zhang X, Wu G, Ren P, Wu J, Li M, Li J, Song L. miR-508 sustains phosphoinositide signalling and promotes aggressive phenotype of oesophageal squamous cell carcinoma. Nature communications. 2014; 5:4620.

35. Sun N, Ye L, Chang T, Li X, Li X. microRNA-195-Cdc42 axis acts as a prognostic factor of esophageal squamous cell carcinoma. International journal of clinical and experimental pathology. 2014; 7:6871-6879.

36. Ide S, Toiyama Y, Shimura T, Kawamura M, Yasuda H, Saigusa S, Ohi M, Tanaka J, Mohri Y, Kusunoki M. MicroRNA-503 promotes tumor progression and acts as a novel biomarker for prognosis in oesophageal cancer. Anticancer research. 2015; 35:1447-1451.

37. Ge C, Wu S, Wang W, Liu Z, Zhang J, Wang Z, Li R, Zhang Z, Li Z, Dong S, Wang Y, Xue Y, Yang J, et al. miR-942 promotes cancer stem cell-like traits in esophageal squamous cell carcinoma through activation of $\mathrm{Wnt} / \beta$ catenin signalling pathway. Oncotarget. 2015; 6:1096410977. doi: 10.18632/oncotarget.3696.

38. Ueda T, Volinia S, Okumura H, Shimizu M, Taccioli C, Rossi S, Alder H, Liu C, Oue N, Yasui W, Yoshida K, Sasaki H, Nomura S, et al. Relation between microRNA 
expression and progression and prognosis of gastric cancer: a microRNA expression analysis. The Lancet Oncology. 2010; 134:1926-1934.

39. Nishida N, Mimori K, Fabbri M, Yokobori T, Sudo T, Tanaka F, Shibata K, Ishii H, Doki Y, Mori M. MicroRNA$125 \mathrm{a}-5 \mathrm{p}$ is an independent prognostic factor in gastric cancer and inhibits the proliferation of human gastric cancer cells in combination with trastuzumab. Clin Cancer Res. 2011; 17:2725-33.

40. Iwaya T, Fukagawa T, Suzuki Y, Takahashi Y, Sawada G, Ishibashi M, Kurashige J, Sudo T, Tanaka F, Shibata K, Endo F, Katagiri H, Ishida K, et al. Contrasting expression patterns of histone mRNA and microRNA-760 in patients with gastric cancer. Clin Cancer Res. 2013; 19:6438-6449.

41. Deng M, Tan HL, Lu XH, Liu MY, Lu XM, Gu YX, Liu JF, He ZM. MiR-26a suppresses tumor growth and metastasis by targeting FGF9 in gastric cancer. PLoS One. 2013; 8:e72662.

42. Tang H, Deng M, Tang Y, Xie X, Guo J, Kong Y, Ye F, Su Q, Xie X. miR-200b and miR-200c as prognostic factors and mediators of gastric cancer cell progression. Clin Cancer Res. 2013; 19:5602-5612.

43. Tan Z, Jiang H, Wu Y, Xie L, Dai W, Tang H, Tang S. MiR-185 is an independent prognosis factor and suppresses tumor metastasis in gastric cancer. Mol Cell Biochem. 2014; 386:223-231.

44. Huang D, Wang H, Liu R, Li H, Ge S, Bai M, Deng T, Yao G, Ba Y. MiRNA27a is a biomarker for predicting chemosensitivity and prognosis in metastatic or recurrent gastric cancer. J Cell Biochem. 2014; 115:549-56.

45. Lim JY, Yoon SO, Seol SY, Hong SW, Kim JW, Choi SH, Lee JS, Cho JY. Overexpression of miR-196b and HOXA10 characterize a poor-prognosis gastric cancer subtype. World J Gastroenterol. 2013; 19:7078-7088.

46. Wang W, Li F, Zhang Y, Tu T, Yang Q, Gao X. Reduced expression of miR-22 in gastric cancer is related to clinicopathologic characteristics or patient prognosis. Diagn Pathol. 2013; 8:102.

47. Yang TS, Yang XH, Chen X, Wang X, Hua J, Zhou D, Zhou B. MicroRNA-106b in cancer-associated fibroblasts from gastric cancer promotes cell migration and invasion by targeting PTEN. FEBS Lett. 2014; 588:2162-2169.

48. Cheng Z, Liu F, Wang G, Wang G, Li Y, Zhang H, Li F. MiR-133 is a key negative regulator of CDC42-PAK pathway in gastric cancer. Cell Signal. 2014; 26:2667-2673.

49. Xin SY, Feng XS, Zhou LQ, Sun JJ, Gao XL, Yao GL. Reduced expression of circulating microRNA-218 in gastric cancer and correlation with tumor invasion and prognosis. World J Gastroenterol. 2014; 20: 6906-6911.

50. Chen DL, Zhang DS, Lu YX, Chen LZ, Zeng ZL, He MM, Wang FH, Li YH, Zhang HZ, Pelicano H, Zhang W, $\mathrm{Xu}$ RH. microRNA-217 inhibits tumor progression and metastasis by downregulating EZH2 and predicts favorable prognosis in gastric cancer. Oncotarget. 2015; 6:10868-
10879. doi: 10.18632/oncotarget.3451.

51. Zhang L, Ding Y, Yuan Z, Liu J, Sun J, Lei F, Wu S, Li $\mathrm{S}$, Zhang D. MicroRNA-500 sustains nuclear factor- $\kappa \mathrm{B}$ activation and induces gastric cancer cell proliferation and resistance to apoptosis. Oncotarget. 2015; 6:2483-2495. doi: 10.18632/oncotarget.2800.

52. Deng J, Lei W, Xiang X, Zhang L, Yu F, Chen J, Feng M, Xiong J. MicroRNA-506 inhibits gastric cancer proliferation and invasion by directly targeting Yap1. Tumour Biol. 2015; 36:6823-6831.

53. Li Y, Gao Y, Xu Y, Ma H, Yang M. Down-regulation of miR-326 is associated with poor prognosis and promotes growth and metastasis by targeting FSCN1 in gastric cancer. Growth Factors. 2015; 33:267-274.

54. Chen H, Ren C, Han C, Wang D, Chen Y, Fu D. Expression and prognostic value of miR-486-5p in patients with gastric adenocarcinoma. PLoS One. 2015; 10:e0119384.

55. Gong J, Cui Z, Li L, Ma Q, Wang Q, Gao Y, Sun H. MicroRNA-25 promotes gastric cancer proliferation, invasion, and migration by directly targeting F-box and WD-40 Domain Protein 7, FBXW7. Tumour Biol. 2015; 36:7831-7840.

56. Chen X, Wang Y, Zang W, Du Y, Li M, Zhao C. MiR-194 targets RBX1 gene to modulate proliferation and migration of gastric cancer cells. Tumour Biol. 2015; 36:2393-2401.

57. Su Z, Zhao J, Rong Z, Geng W, Wang Z. MiR-451, a potential prognostic biomarker and tumor suppressor for gastric cancer. Int J Clin Exp Pathol 2015; 8:9154-9160.

58. Shi H, Han J, Yue S, Zhang T, Zhu W, Zhang D. Prognostic significance of combined microRNA-206 and CyclinD2 in gastric cancer patients after curative surgery: A retrospective cohort study. Biomed Pharmacother. 2015; 71:210-215.

59. Hui WT, Ma XB, Zan Y, Wang XJ, Dong L. Prognostic Significance of MiR-34a Expression in Patients with Gastric Cancer after Radical Gastrectomy. Chin Med J (Engl). 2015; 128:2632-7.

60. Díaz R, Silva J, García JM, Lorenzo Y, García V, Peña C, Rodríguez R, Muñoz C, García F, Bonilla F, Domínguez G. Deregulated expression of miR-106a predicts survival in human colon cancer patients. Genes Chromosomes Cancer. 2008; 47:794-802.

61. Nishimura J, Handa R, Yamamoto H, Tanaka F, Shibata K, Mimori K, Takemasa I, Mizushima T, Ikeda M, Sekimoto M, Idhii H, Doki Y, Mori M. MicroRNA-181a is associated with poor prognosis of colorectal cancer. Oncol Rep. 2012; 28:2221-2226.

62. Zhou T, Zhang GJ, Zhou H, Xiao HX, Li Y. Overexpression of microRNA-183 in human colorectal cancer and its clinical significance. Eur J Gastroenterol Hepatol. 2014; $1-5$.

63. Qian J, Jiang B, Li M, Chen J. Prognostic significance of microRNA-16 expression in human colorectal cancer. World J Surg. 2013; 37:2944-2949. 
64. Liu X, Duan B, Dong Y, He CZ, Zhou HM, Sheng HH, Gao HJ, Zhang XZ. MicroRNA-139-3p indicates a poor prognosis of colon cancer. Int J Clin Exp Pathol. 2014; 7:8046-8052.

65. Ma F, Song H, Guo B, Zhang Y, Zheng Y, Lin C, Wu Y, Guan G, Sha R, Zhou Q, Wang D, Zhou X, Li J, et al. MiR361-5p inhibits colorectal and gastric cancer growth and metastasis by targeting staphylococcal nuclease domain containing-1. Oncotarget. 2015; 6:17404-17416. doi: 10.18632/oncotarget.3744.

66. Gopalan V, Pillai S, Ebrahimi F, Salajegheh A, Lam TC, Le TK, Langsford N, Ho YH, Smith RA, Lam AK. Regulation of microRNA-1288 in colorectal cancer: altered expression and its clinicopathological significance. Mol Carcinog. 2014; 53:E36-E44.

67. Nguyen GH, Schetter AJ, Chou DB, Bowman ED, Zhao R, Hawkes JE, Mathe EA, Kumamoto K, Zhao Y, Budhu A, Hagiwara N, Wang XW, Miyashita M, et al. Inflammatory and microRNA gene expression as prognostic classifier of Barrett's-associated esophageal adenocarcinoma. Clin Cancer Res. 2010; 16:5824-5834.

68. Nie J, Liu L, Zheng W, Chen L, Wu X, Xu Y, Du XH, Han WD. MicroRNA-365, down-regulated in colon cancer, inhibits cell cycle progression and promotes apoptosis of colon cancer cells by probably targeting Cyclin D1 and Bcl2. Carcinogenesis. 2012; 33:220-225.

69. Sun K, Su G, Deng H, Dong JQ, Lei ST, Li GX. Relationship between miRNA-338-3p expression and progression and prognosis of human colorectal carcinoma. Chin Med J (Engl). 2014; 127:1884-1890.

70. Zhou X, Wang Y, Shan B, Han J, Zhu HF, Lv YL, Fan XJ, Sang MX, Liu XD, Liu W. The downregulation of miR200c/141 promotes ZEB1/2 expression and gastric cancer progression. Med Oncol. 2015; 32:428.

71. Yue B, Sun B, Liu C, Zhao S, Zhang D, Yu F, Yan D. Long non-coding RNA Fer-1-like protein 4 suppresses oncogenesis and exhibits prognostic value by associating with miR-106a-5p in colon cancer. Cancer Sci. 2015; 106:1323-1332.

72. Yan Z, Xiong Y, Xu W, Gao J, Cheng Y, Wang Z, Chen F. Identification of hsa-miR-335 as a prognostic signature in gastric cancer. PLoS One. 2012; 7:e40037.

73. Kang WK, Lee JK, Oh ST, Lee SH, Jung CK. Stromal expression of miR-21 in T3-4a colorectal cancer is an independent predictor of early tumor relapse. BMC Gastroenterol. 2015; 15:1-10.

74. Xu Y, Sun J, Xu J, Li Q, Guo Y, Zhang Q. miR-21 Is a Promising Novel Biomarker for Lymph Node Metastasis in Patients with Gastric Cancer. Gastroenterol Res Pract. 2012; 1-5.

75. Jamali Z, Aminabadi NA, Attaran R, Pournagiazar F, Oskouei SG, Ahmadpour F. MicroRNAs as prognostic molecular signatures in human head and neck squamous cell carcinoma: a systematic review and meta-analysis. Oral Oncol. 2015; 1-11.

76. Liu GH, Zhou ZG, Chen R, Wang MJ, Zhou B, Li Y, Sun XF. Serum miR-21 and miR-92a as biomarkers in the diagnosis and prognosis of colorectal cancer. Tumour Biol. $2013 ; 34: 2175-2181$

77. Tierney JF, Stewart LA, Ghersi D, Burdett S, Sydes MR. Practical methods for incorporating summary time-to-event data into meta-analysis. Trials. 2007; 8:1-16.

78. Stroup DF, Berlin JA, Morton SC, Olkin I, Williamson GD, Rennie D, Moher D, Becker BJ, Sipe TA, Thacker SB. Meta-analysis of Observational Studies in Epidemiology. JAMA. 2000; 283:2008-2012. 